\title{
The Relation between Energy, Economy and Environment in China's Industrial Sector: Based on Energy Saving
}

\author{
http://dx.doi.org/10.3991/ijoe.v9iS4.2656 \\ Qiang Han $^{1}$, and Yong Zhou ${ }^{2}$ \\ ${ }^{1}$ Shandong University of Finance and Economics, Jinan, China \\ ${ }^{2}$ Institute of Science and Technology Development Strategy of Shandong Province, Jinan, China
}

\begin{abstract}
Energy saving is important for our society, and industry should be focused because of its high energy consumption. This paper used the grey correlation degree method to discuss the relation between economic development, environmental protection and industrial energy consumption in China, gave harmonious development model for 3E (Energy - Economy Environment) system, and computed contribution rate for energy consumption decrease based on industrial indexes. Results show that energy utilization efficiency of industry is low, industrial energy consumption promotes the increase of waste, industrial added value blocks the decrease of energy consumption intensity, and the decrease of industrial energy consumption intensity is vital. Hence, energy saving of industry is imperative, which can be achieved by measures in industry restructuring, technology research, administration mode, legal construction, and recycling economy.
\end{abstract}

Index Terms-Industrial Energy Consumption, EnergyEconomy-Environment Compounding System, Industrial Energy Saving, Grey Correlation Analysis

\section{INTRODUCTION}

In 2010, the proportion of three industries in China was 10.1 percent, 46.8 percent and 43.1 percent, respectively, and industrial added value accounts for 85.7 percent of secondary industry. Industry is still the most important economic sector and energy consumer, which energy consumption shares more than 70 percent of the society. Consequent environment problem is getting more and more severe in our times depending on fossil energy. So, to cope with global climate change, with the trend of energy-saving and emission-reduction, energy consumption per unit of output value and environmental pollution with economy development should be further reduced. A new harmonious road for energy, economy and environment should be fished out.

At present, research fruits about energy consumption of China are classified in four aspects:

The first is about the relation between energy consumption and economic growth. Ref. [1] re-examined the energy-GDP relationship for the US for the period 1946-2000 by redefining energy in terms of exergy, and inferred that output growth does not drive increased energy consumption. Ref. [2] uses multivariate cointegration Granger causality tests to investigate the correlations between carbon dioxide emissions, energy consumption and economic growth in China, and concluded that exclusive pursuit of economic growth will increase energy consumption. Ref. [3] examined the relationship between energy consumption and economic growth for six Central American countries, and the Granger-causality results indicated the presence of both short-run and long-run causality from energy consumption to economic growth which supports the growth hypothesis.

The second is about energy utilization efficiency. Improving energy efficiency was taken as an inevitable choice for the protection of national energy security and sustained economic growth in [4]. Early understanding of energy efficiency was to provide the same energy services by reducing energy inputs in [5]. Ref. [6] gave the clear description of the systematic process of energy utilization efficiency, and employed data envelopment analysis to evaluate energy utilization efficiency between China and Taiwan from 2002 to 2007.

The third is about energy consumption structure. Ref. [7] estimated the scale of fossil energy subsidies of China in 2007 with price-gap approach and discussed the possibility and potential of improving energy consumption structure. Ref. [8] analyzed the situation and trend of China's energy consumption structure, and indicated that China will not enter the oil era, natural gas and non-fossil energy will rapidly develop. Ref. [9] thought a full analysis of factors that may relate to energy intensity (e.g. energy consumption structure, economic structure) should be conducted before making energy policies. In order to decrease energy intensity, Chinese government must continue to promote the upgrade of economic structure.

The fourth is about energy use in view of environmental protection. Ref. [10] constructed synergy evaluation model about energy, economy, society and environment. Ref. [11] thought that in practice, traditional administrative system in China has changed, which has always favored economic growth over environmental protection. Also, China has to evolve a low carbon industrialization model. Ref. [12] took it as the key to the success of sustainable development initiatives.

Although above fruits studied energy use in different respects and gave much reference for further research, little was focused on industrial sector of China. As the most important field for energy saving, its contribution rate should be decomposed. This paper will analyze industrial energy use in view of energy saving. The rest is organized as follows: the second part makes grey 
correlation analysis between industrial energy consumption, economic growth and environmental protection; in section 3 , one harmonious development model for energy-economy-environment compounding system is designed; then, in the fourth part, contribution rate is decomposed during energy consumption decrease based on industrial indexes; at last, conclusions and proposals are brought forward.

\section{GREY CORRELATION ANALYSIS OF INDUSTRIAL ENERGY CONSUMPTION WITH ECONOMIC GROWTH AND ENVIRONMENTAL PROTECTION}

Grey correlation analysis finds out otherness and similarity among elements by distance between the reference sequence and comparative sequence. Based on geometrical shape closeness of behavioral sequence, this method determines influence degree between factors and contribution degree of factors to behavior.

\section{A. Selection of Index}

In light of too short time span for full historical data, evaluation indexes mustn't be too much, or the correlation will be demonstrated impertinently. Industrial final energy consumption is adopted to reflect the index of industrial energy consumption, which is worked out based on coal consumption of power generation, industrial added value to reflect the index of economic development, and industrial three-waste discharge to be the index of environmental protection. Corresponding data can be seen in Table 1.

\section{B. Assignment of Reference Sequence and Comparative Sequence}

After needed data is prepared, the analysis may move on with industrial energy consumption as the reference sequence, and industrial added value and three-waste discharge (output) as comparative sequence.

\section{Non-dimensional Treatment of Data}

Time sequences, with different unit, need pretreatment to make elements in original sequences be dimensionless value. Practicable pretreatment methods include initialization, equalization, and standardization. For the selected sequences are growing steadily, the first one is adopted, which operation is to divide the first number by all the data in the same sequence. Then, one new sequence with development rate of fixed base can be obtained.

\section{Computation of Correlation Coefficient}

Suppose initialized industrial energy consumption sequence be $\{x(t)\}$, and others are $y_{i}(t)(i=1,2,3,4 ; t=$ 1995, ......, 2010) respectively. Correlation coefficient between $x(t)$ and $y_{i}(t)$ in certain year $\mathrm{t}$ is denoted by $L_{i}(t)$, then

$$
L_{i}(t)=\frac{\min _{i} \min _{t}\left|x(t)-y_{i}(t)\right|+\zeta \max _{i} \max _{t}\left|x(t)-y_{i}(t)\right|}{\left|x(t)-y_{i}(t)\right|+\zeta \max _{i} \max _{t}\left|x(t)-y_{i}(t)\right|}
$$

where, $\zeta \in[0,1]$ is resolution ratio and let it be 0.5 as usual; $\min _{i} \min _{t}\left|x(t)-y_{i}(t)\right|$ is two-level minimum difference, in which $\min$ is the first-level minimum difference, indicating the minimum distance between points in $y_{i}(t)$ and $x(t)$, and min min means that after $\min$ is found in each curve, the minimum of $\min _{t}$ is got among all the curves $i=1,2,3,4 ; \max _{i} \max \left|x(t)-y_{i}(t)\right|$ is two-level maximum difference, which meaning is similar to the minimum one.

\section{E. Computation of Correlation Degree}

After correlation coefficients between each sequence and industrial energy consumption in each year are added up and averaged, then correlation degree $r_{i}$. can be computed as follows:

TABLE I.

ORIGINAL DATA OF INDUSTRY ENERGY CONSUMPTION, GROSS VALUE ADDED AND THE THREE WASTE

\begin{tabular}{|c|c|c|c|c|c|}
\hline Year & $\begin{array}{c}\text { Industrial energy } \\
\text { consumption } \\
\left(10^{4} \text { tce }\right)\end{array}$ & $\begin{array}{c}\text { Industrial added value } \\
\left(10^{8} \mathrm{RMB} \text { Yuan }\right)\end{array}$ & $\begin{array}{c}\text { Discharge of industrial } \\
\text { waste water } \\
\left(10^{8} \text { ton }\right)\end{array}$ & $\begin{array}{c}\text { Discharge of industrial } \\
\mathrm{SO}_{2} \\
\left(10^{4} \text { ton }\right) \\
\end{array}$ & $\begin{array}{c}\text { Production of industrial } \\
\text { solid waste } \\
\left(10^{4} \text { ton }\right)\end{array}$ \\
\hline 1995 & 96191 & 24951 & 222 & 1405 & 64474 \\
\hline 1996 & 90566 & 29448 & 206 & 1397 & 65897 \\
\hline 1997 & 90922 & 32921 & 188 & 1363 & 65750 \\
\hline 1998 & 91252 & 34018 & 201 & 1600 & 80043 \\
\hline 1999 & 94459 & 35861 & 197 & 1460 & 78442 \\
\hline 2000 & 97597 & 40034 & 194 & 1615 & 81608 \\
\hline 2001 & 100690 & 43581 & 203 & 1567 & 88840 \\
\hline 2002 & 106377 & 47431 & 207 & 1562 & 94509 \\
\hline 2003 & 123122 & 54946 & 212 & 1791 & 100428 \\
\hline 2004 & 143607 & 65210 & 221 & 1891 & 120030 \\
\hline 2005 & 158767 & 77231 & 243 & 2168 & 134449 \\
\hline 2006 & 174225 & 91311 & 240 & 2238 & 151541 \\
\hline 2007 & 189032 & 110535 & 221 & 2140 & 175632 \\
\hline 2008 & 196832 & 130260 & 217 & 1991 & 177721 \\
\hline 2009 & 205322 & 135240 & 209 & 1694 & 203943 \\
\hline 2010 & 211626 & 160867 & 212 & 1705 & 240944 \\
\hline
\end{tabular}

Data resource: China Statistical Yearbook 1996-2011, China Energy Statistical Yearbook 2008-2011. 
Results are shown in Table II.

TABLE II.

CORRELATION DEGREE BETWEEN INDUSTRIAL ENERGY CONSUMPTION AND OTHER FACTORS

\begin{tabular}{|c|c|c|c|l|}
\hline Item & $\begin{array}{c}\text { Added } \\
\text { value }\end{array}$ & $\begin{array}{c}\text { Waste } \\
\text { water }\end{array}$ & \multicolumn{1}{|c|}{$\mathbf{S O}_{2}$} & solid waste \\
\hline Correlation degree & 0.6461 & 0.8308 & 0.9055 & 0.8244 \\
\hline
\end{tabular}

\section{F. Interpretation of the Result}

It can be seen from Table 2 that industrial energy consumption has correlations with industrial added value and three-waste discharge (output) in varying degrees, which seems valuable to put energy into use. It, however, has the lowest relation with industrial added value, that is, present energy utilization efficiency in industrial sector is a bit low and certain energy input can't cause proportional output. For example, in 2010, China's energy consumption per industrial added value of $10^{4}$ RMB Yuan is at the level of 1.72 tce (ton of standard coal equivalent). But, there is great correlation degree between industrial energy consumption and three-wastes discharge (output). That of discharge of industrial $\mathrm{SO}_{2}$ reaches 0.9055 , which shows that industrial energy use helps the increase of three-waste output. What's more, main energy source in China is coal that needs further processing or clean energy substituting, aiming to reduce waste output in using. From the prospect of environmental protection merely, lessening fossil energy will make environmental situation distinctly.

\section{HARMONIOUS DEVELOPMENT MODEL OF ENERGY- ECONOMY-ENVIRONMENT SYSTEM}

Energy system, economy system and environment system can still constitute energy-economy-environment (3E) compounding system because of the close relation among them, although they in themselves are very complex. One sub-system may produce positive effect to others, and negative effect as well. This compounding system embodies its economic characteristic, so economy sub-system is its core. further, the core of economy subsystem is industry.

Based on principle in dynamics, running orbit of compounding system can be portrayed in Logistic Equation:

$$
\frac{d S}{d t}=k S\left(1-\frac{S}{C}\right)
$$

where, $S$ is the state of compounding system, $k$ denotes its variance ratio, $C$ indicates restrictions about energy and environment, and $t$ shows time sequence.

Any system will maintain its optimum steady state finally, in which promoting and restricting effects between each element are balanceable. Influence produced by economy and energy sub-system is restricted within the capacity of environment sub-system. Utilization speed of fossil energy in energy sub-system is not more than that of finding them. Energy sub-system can support the development of economy sub-system. Generally, compounding system will go through the following four stage, as shown in Equation 3.
The first stage is balanced period, which is preindustrial phase. In this period, demand of energy is steady, most of which is woody material, and environment system has better self-control effect.

The second is deteriorating period, which is industrial intermediary and preceding phase. With the development of human society, demand of fossil energy is getting high, which produces damage to environment gradually. Damage exceeds slowly its self-adjust ability. Worsening indication comes into being and will be intensified.

The third stage is transforming period, which is industrial middle and later phase. Excessive exploitation makes fossil energy less and less. To achieve sustainable development and maintain human being's economic development, man should break through the ties of stock of fossil energy and environmental damage, and widen environment capacity. In this period, a part of non-fossil energy, such as nuclear energy, wind energy, and solar energy, gets exploited. Environment system is getting better and produced damage is restored gradually.

The fourth stage is new balanced period, which is postindustrial phase. In this period, non-fossil energy starts to be popularized, consumption of fossil energy falls sharply and environment system returns as in the first period.

It is not wise to pull economic growth by high energy input, but under the background of recovering slowly from global economic crisis, the development mode with industry as the main body will continue, which also go on causing inharmonious factors for China's economy. In 3E system, energy and environment part belongs to natural system, and economic part is in the lead. Transforming from imbalance to balance is realized by human being's action affecting the former two. So, global management should be made by putting industry into the whole social economic system, exerting more positive feedback effect, and leading actively the energy and environment subsystem along the harmonious road. These positive feedback effects consist mainly of structure modification, technical progress, exploitation of new energy, and strengthening of administration, etc. Harmonious development model of $3 \mathrm{E}$ compounding system can be seen in Fig. 1.

\section{CONTRIBUTION RATE DECOMPOSITION IN ENERGY CONSUMPTION DECREASE BASED ON INDUSTRIAL INDEXES}

Enhancing energy utilization efficiency and reducing energy consumption intensity are important measures to save energy. Factor de-

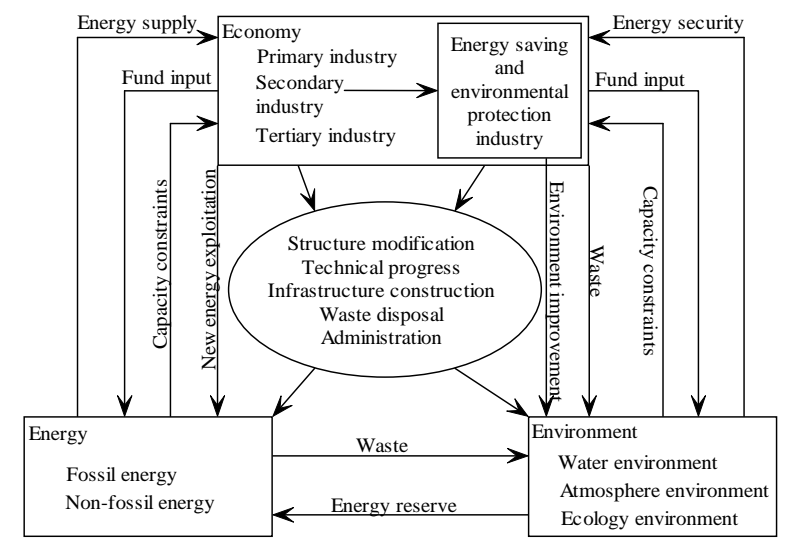

Figure 1. Coordination development model of 3E system 
composition method is the main tools to decompose quantitatively influencing factors in field of energy and environment research. Here, the Laspeyres' factor decomposition is adopted to analyze contribution rate of industry in reducing comprehensive energy consumption intensity of China.

Comprehensive energy consumption intensity (CECI) can be decomposed as follows:

$$
C E C I=\frac{G E C}{G D P}=\frac{G E C}{G E C_{I}} \times \frac{G E C_{I}}{G D P_{I}} \times \frac{G D P_{I}}{G D P}
$$

where, $G E C$ represents general energy consumption, $G D P$ means general domestic production, $G E C_{I}$ implies general energy consumption of industry, and $G D P_{I}$ shows industrial added value.

Equation 4 makes it clear that $C E C_{I}$ can be decomposed into product of three factors, that is, reciprocal of the percentage of industrial energy consumption, industrial energy consumption intensity (denoted by $C E C I_{I}$ in the following text), and the percentage of industrial added value. Then variation of $C E C_{I}$ will come from effect of them, which are denoted by $E_{f f e c t} t_{R i o(1 / E C)}$, Effect $_{C E C I())}$, Effect $t_{R i o(G D P)}$, respectively.

$$
\begin{aligned}
& \Delta C E C I=C E C I^{\mathrm{T}}-C E C I^{0} \\
& =\text { Effect }_{\text {Rio }(1 / E c)}+\text { Effect }_{C E C I(I)}+\text { Effect }_{\text {Rio(GDP) }}
\end{aligned}
$$

The expression of each decomposed item is as follows:

$$
\begin{aligned}
& E f f e c t_{R i o(1 / E C)}=\left[\left(\frac{G E C}{G E C_{I}}\right)^{\mathrm{T}}-\left(\frac{G E C}{G E C_{I}}\right)^{0}\right] \times\left(\frac{G E C_{I}}{G D P_{I}}\right)^{\mathrm{T}} \times\left(\frac{G D P_{I}}{G D P}\right)^{\mathrm{T}} \\
& \text { Effect }_{C E C I(I)}=\left[\left(\frac{G E C_{I}}{G D P_{I}}\right)^{\mathrm{T}}-\left(\frac{G E C_{I}}{G D P_{I}}\right)^{0}\right] \times\left(\frac{G E C}{G E C_{I}}\right)^{0} \times\left(\frac{G D P_{I}}{G D P}\right)^{\mathrm{T}} \\
& E f f e c t_{R i(G D P)}=\left[\left(\frac{G D P_{I}}{G D P}\right)^{\mathrm{T}}-\left(\frac{G D P_{I}}{G D P}\right)^{0}\right] \times\left(\frac{G E C}{G E C_{I}}\right)^{0} \times\left(\frac{G E C_{I}}{G D P_{I}}\right)^{0}
\end{aligned}
$$

where, superscript $T$ and 0 represent the terminal and initial moment in comparison, respectively. It can be proven easily that the above decomposition method is complete, with no residuals item. Final decomposition result is listed in Table III.

TABLE III

RELATION BETWEEN CHINA'S COMPREHENSIVE ENERGY CONSUMPTION INTENSITY AND THE OTHER THREE INDEXES

\begin{tabular}{|c|c|c|c|}
\hline $\begin{array}{c}\text { Contribution } \\
\text { rate in time } \\
\text { span (\%) }\end{array}$ & Effect $_{\text {Rio(1/EC) }}$ & Effect $_{\text {CECI(I) }}$ & Effect $_{\text {Rio(GDP) }}$ \\
\hline $2005-2006$ & 0.14 & 106.36 & -6.51 \\
\hline $2005-2007$ & -0.09 & 111.02 & -10.93 \\
\hline $2005-2008$ & 3.16 & 105.71 & -8.87 \\
\hline $2005-2009$ & -0.09 & 104.28 & -4.19 \\
\hline $2005-2010$ & -2.21 & 114.12 & -11.91 \\
\hline
\end{tabular}

Data resource: China Statistical Yearbook 2006-2011, China Energy Statistical Yearbook 2006-2011.
From Table III, factors influencing $C E C I$ in the five years obey the following uniform tendency:

Transversely in each time span, percentage of industrial energy consumption has negligible effect on variation of $C E C I$, the reduction of industrial energy consumption intensity takes indubitable and decisive role in the decrease of $C E C I$, and on the contrary, industrial added value produces negative effect, that is, more industrial added value will block the further decrease of $C E C I$, which means that industry restructuring is imperative and secondary industry and industry should slowly give its leader position to tertiary industry. So, how much energy is used by industry is not the key, while industrial added value seems more important, because the current industrial energy consumption is a little high, and too much energy is input when certain output is produced, which leads to the negative effect for reducing $C E C I$.

Verticality in each time span, industrial energy saving still has heavy responsibilities on its shoulders. Its absolute decrease of energy consumption intensity is always more than that of CECI, and it has been the important force in achieving the energy saving objective. Also, both positive effect from $C E C I_{I}$ and negative effect from the percentage of industrial value added are on the down, the positive effect of percentage of $G E C_{I}$, however, tells its spiraling tendency. Hence, energy saving must be one important and arduous task. In the near future, rebounding may happen out of accidental factor. In the medium-term and long-term future, with continual and further adjustment of industry and economy structure, industrial energy consumption will keep going down. Percentage of industrial added value won't be important any longer, which effect and that of percentage of industrial energy consumption are on the shift. Equilibrium point between their positive and negative effect must be reached. In the long-term future, the effect of industrial energy consumption will on the lead. In that time, industrial energy consumption has reached a comparatively lower level, and potential of more decrease is getting small.

\section{CONCLUSIONS}

Energy plays important supporting role in industrial development. Fossil energy occupying an leading position, however, goes against environmental protection. So, energy is the key to solve the problem among them. Industry not only is the undoubted driving force for China's economic progress, but also obligatorily assumes required energy-saving duty. China should move on along the principle of energy saving making progress, progress making energy saving, and energy saving while developing. Under the premise of continuous increase of industrial added value, the whole society forges ahead harmoniously, saving energy by measures about industry restructuring, technology research, administration mode, legal construction, and recycling economy.

\section{REFERENCES}

[1] B. S. Warr and R. U. Ayres, "Evidence of causality between the quantity and quality of energy consumption and economic growth," Energy, vol. 35, no. 4, pp. 1688-1693, 2010. http://dx.doi.org/10.1016/j.energy.2009.12.017

[2] C. Chang, "A multivariate causality test of carbon dioxide emissions, energy consumption and economic growth in China,” 
Applied Energy, vol. 87, no. 11, pp. 3533-3537, 2010. http://dx.doi.org/10.1016/j.apenergy.2010.05.004

[3] N. Apergis and J. E. Payne, "Energy consumption and economic growth in Central America: Evidence from a panel cointegration and error correction model," Energy Economics, vol. 31, no. 2, pp. 211-216, 2009. http://dx.doi.org/10.1016/j.eneco.2008.09.002

[4] I. S. Wing, "Explaining the declining energy intensity of the U.S. economy," Resource and Energy Economics, no. 30, pp. 21-49, 2008. http://dx.doi.org/10.1016/j.reseneeco.2007.03.001

[5] J. R. Jiang, "Research on energy efficiency of China under the constraints of soft input," Dissertation of Lanzhou University, 2010.

[6] T. Yeh, T. Chen and P. Lai, “A comparative study of energy utilization efficiency between Taiwan and China," Energy Policy, vol. 38, no. 5, pp. 2386-2394, 2010. http://dx.doi.org/10.1016/ j.enpol.2009.12.030

[7] W. Liu and H. Li, "Improving energy consumption structure: A comprehensive assessment of fossil energy subsidies reform in China," Energy Policy, vol. 39, no. 7, pp. 4134-4143, 2011. http://dx.doi.org/10.1016/j.enpol.2011.04.013

[8] C. Yuan, D. Song, B. Guo and N. Xie, "Prediction of China's energy consumption structure," Kybernetes, vol. 41, no. 5/6, pp. 559-567, 2012.

[9] T. Feng, L. Sun and Y. Zhang, "The relationship between energy consumption structure, economic structure and energy intensity in China,” Energy Policy, vol. 37, no. 12, pp. 5475-5483, 2009. http://dx.doi.org/10.1016/j.enpol.2009.08.008

[10] F. Luo, "Study on the optimization of Chinese energy consumption structure based on synergetics," Dissertation of China University of Mining and Technology, 2009.
[11] Q. Wang and Y. Chen, "Energy saving and emission reduction revolutionizing China's environmental protection," Renewable and Sustainable Energy Reviews, vol. 14, no. 1, pp. 535-539, 2010. http://dx.doi.org/10.1016/j.rser.2009.08.006

[12] J. He, J. Deng and M. Su, "CO2 emission from China's energy sector and strategy for its control," Energy, vol. 35, no. 11, pp. 4494-4498, 2010. http://dx.doi.org/10.1016/j.energy.2009.04.009

\section{AUTHORS}

Qiang Han is with the School of Management Science and Engineering, Shandong University of Finance and Economics, Jinan, Shandong Province 250014 China (email: hanqiang18@sina.com).

Yong Zhou is with the Institute of Science and Technology Development Strategy of Shandong Province, Jinan, Shandong Province 250014 China (e-mail: bft@qq. com).

This work was supported in part by the Ministry of Education, Humanities and Social Science Projects of PRC (09YJC630141), Shandong Province Soft Science Project (2010RKMA1001). This article is an extended and modified version of a paper presented at the International Conference on Mechanical Engineering, Automation and Material Science (MEAMS2012), held 22-23 December 2012, Wuhan, China. Manuscript received 09 April 2013. Published as submitted by the authors 01 May 2013.. 